\title{
Genetic Diversity in Natural Populations of New World Leishmania
}

\author{
Elisa Cupolillo/ ${ }^{+}$, Hooman Momen*, Gabriel Grimaldi Jr
}

\author{
Laboratório de Leishmaniose, Departamento de Imunologia *Laboratório de Sistemática Bioquímica, \\ Departamento de Bioquímica e Biologia Molecular, Instituto Oswaldo Cruz, Av. Brasil 4365, 21045-900 \\ Rio de Janeiro, RJ, Brasil
}

\begin{abstract}
Our results have shown the wide diversity of parasites within New World Leishmania. Biochemical and molecular characterization of species within the genus has revealed that much of the population heterogeneity has a genetic basis. The source of genetic diversity among Leishmania appears to arise from predominantly asexual, clonal reproduction, although occasional bouts of sexual reproduction can not be ruled out. Genetic variation is extensive with some clones widely distributed and others seemingly unique and localized to a particular endemic focus. Epidemiological studies of leishmaniasis has been directed to the ecology and dynamics of transmission of Leishmania species/variants, particularly in localized areas. Future research using molecular techniques should aim to identify and follow Leishmania types in nature and correlate genetic typing with important clinical characteristics such as virulence, pathogenicity, drug resistance and antigenic variation. The epidemiological significance of such variation not only has important implications for the control of the leishmaniases, but would also help to elucidate the evolutionary biology of the causative agents.
\end{abstract}

Key words: New World Leishmania - leishmaniasis - epidemiology - molecular characterization

Genetic variation in medically important protozoan parasites and the nature of the reproductive strategies which predispose to such variation are currently the subject of much interest and controversy (Dye et al. 1990, Tibayrenc et al. 1990, 1991, Tibayrenc \& Ayala 1991, Hurst et al. 1992, Sibley \& Boothroyd 1992). This genetic heterogeneity produces different phenotypes which can be associated with a diversity of clinically important manifestations. At least 13 distinct Leishmania species are widespread in the New World and recognized as causing human illness in the Americas. Each of these parasites has a unique zoonotic life cycle, with different sand fly vectors and vertebrate reservoirs (Grimaldi et al. 1989).

Taxonomy of New World Leishmania - Taxonomic studies of leishmanial isolates from the New World indicate tremendous diversity within this genus. A number of new Leishmania species from sylvan areas of the Neotropics have been described recently. Some of these parasites are associated with disease in humans, others seem to be restricted to lower orders of mammals, such as rodents and edentates (Lainson \& Shaw 1987). Since the origi-

\footnotetext{
${ }^{+}$Corresponding author. Fax: +55-21-280.1589. E-mail: ecupoli@gene.dbbm.fiocruz.br

Received 15 June 1998

Accepted 30 July 1998
}

nal description of these parasites, the number of named species has continually increased and several taxa or classification schemes have been proposed (Gardner 1977, Lainson \& Shaw 1979, Rioux et al. 1990), including a subdivision of the genus Leishmania Ross, 1903 into two subgenera, the Viannia and Leishmania, according to the development of the parasite in the gut of sand fly (Lainson \& Shaw 1987).

Except for minor differences in size, all species of Leishmania are morphologically similar. The initial criteria for identification and classification of these parasites were based on extrinsic characteristic, such as clinical manifestations, geographic and epidemiological features, and a variety of other biologic criteria. However, the variation produced by these criteria lead to the development of biochemical, immunological and molecular methods to provide more precise taxonomic markers based on intrinsic characteristics of the parasites themselves. Among the techniques currently in use are isoenzyme electrophoresis, species-specific monoclonal antibodies or DNA probe and analysis of restriction fragment length polymorphism (RFLP) using different DNA sequences as targets (Macedo et al. 1992, Guizani et al. 1994, Mendonza-Leon et al. 1995).

Multilocus enzyme electrophoresis (MLEE) The electrophoretic analysis of isoenzymes has been the most widely used method for characterizing Leishmania (WHO 1990). Isoenzyme electro- 
phoresis has the ability to examine a very large sample of structural genes, providing genetic evidence to distinguish polymorphism within species from differences between species as well as information on the reproductive biology of a given organism (Richardson et al. 1986). The technique involves separating isoenzymes by gel electrophoresis and subsequent visualization of specific enzymes using appropriate staining reactions. Isolates with identical banding patterns (alleles) are usually referred to as zymodemes (Godfrey 1979). Important taxonomic information can be obtained by numerical analysis of the electrophoretic bands, which may vary according to the different alleles or genotypic frequencies of loci that are present in distinct parasite strains (Avise 1975).

A large sample of New World Leishmania has been analyzed in our laboratories by MLEE. The Leishmania strains analyzed until now were grouped in 68 zymodemes (Cupolillo et al. 1994, 1997). Numerical analysis, using phenetic and phylogenetic methods, has demonstrated that the proposed classification of Leishmania in two subgenera, Leishmania and Viannia (Lainson \& Shaw 1987), may represent a valid scheme. The parasites were clustered into five phenetic complexes: L. braziliensis, L. naiffi, L. guyanensis/L. panamensis/L. shawi, L. mexicana, L. major. All $L$. chagasi parasites formed a unique zymodeme closer to L. major than to the other Leishmania species. Within the L. guyanensis/L. panamensis/ $L$. shawi complex, we found some named species to be as similar as variant strains within each of these taxa, which showed that these parasites are closely related as a group. The L. braziliensis and L. naiffi group showed the highest population heterogeneity, presenting 15 and 11 zymodemes, respectively. Some species, like L. lainsoni, $L$. equatorensis and L. colombiensis were shown to be very distinct from the other species, but related among themselves (Cupolillo et al. 1994, 1997) (Fig. 1).

Intergenic region typing - DNA analysis provides a means of examining expressed and nonexpressed sequences of an organism and is not subject to environmental influences. RFLP analysis detects genetic differences by comparing size variation in DNA banding patterns after restriction endonuclease analysis. The technique has been applied to Leishmania focusing basically on the restriction patterns of the minicircle kDNA molecule (Lopes et al. 1984, Pacheco et al. 1986). A PCR based method has been applied in our laboratory to study genetic diversity among parasites, with particular reference to the intraspecific variability that occurs in natural populations of a given Leishmania species. In this methodology we amplify the internal transcribed spacers (ITS) of the rRNA gene by PCR, followed by the digestion of the PCR product with several restriction enzymes. The transcribed noncoding regions of rRNA genes (ITS) show extensive variability. Unlike the non-transcribed spacers, the ITS are relatively small (approx. $1 \mathrm{~kb}$ in Leishmania) and flanked by highly

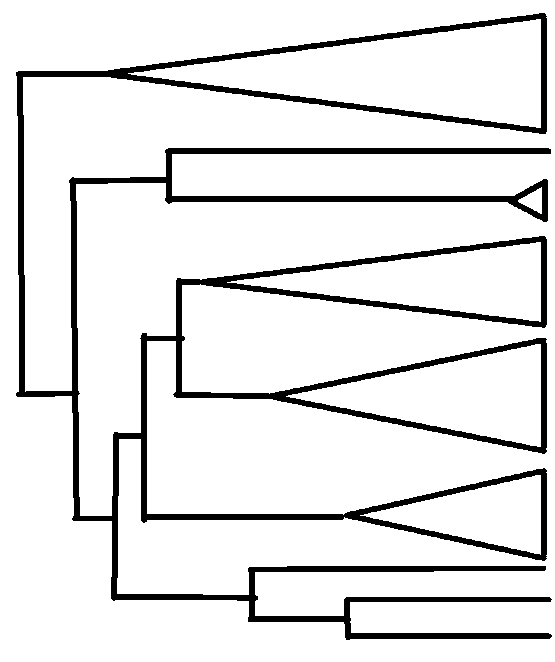

L. mexicana complex and others L.(Leishmania)

L. chagasi

L. major complex

L. naiffi complex

L. braziliensis complex

L. guyanensis complex

L. lainsoni

L. colombiensis

L. equatorensis

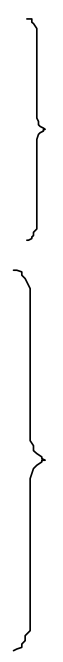

$\begin{array}{lllllllll}0.1 & 02 & 0.3 & 0.4 & 0.5 & 0.6 & 0.7 & 0.8 & 0.9\end{array}$

Jaccard's coefficient

Fig. 1: dendrogram showing the level of similarity and the diversity in each phenetic complex/species. 
conserved segments to which PCR primers can be designed. This approach can potentially be applied in many evolutionary situations and amongst a broad range of target loci, we refered to it as intergenic region typing, or IRT (Cupolillo et al. 1995). We analyzed many Leishmania isolates representing the Viannia subgenus by this method and overall, the ITS clustering showed good agreement with previous organismal or isoenzymatic groupings (Cupolillo et al. 1994). In concordance with the MLEE data L. braziliensis and L. naiffi population showed a high level of polymorphism. If one accepts current species assignments, one interpretation is that both L. naiffi and L. braziliensis are highly polymorphic, possibly due to their evolutionary antiquity. This view was supported by cline of evolutionary distances within $L$. naiffi, without clearly predominant zymodeme or ITS subgroups (Cupolillo et al. 1994, 1995). In contrast, the level of polymorphism was less evident in the group $L$. guyanensis/L. panamensis/L. shawi, reinforcing the idea that these species are very closely related (Lainson \& Shaw, 1987, Thomaz-Soccol et al. 1993, Cupolillo et al. 1994). However, a small polymorphism was observed at the intra-specific level for $L$. guyanensis and $L$. shawi, in contrast to the results obtained by MLEE (Fig. 2). This result points the IRT as a useful method to study genetic variability amongst intra-species Leishmania isolates from an endemic foci.

Genetic variability - The genetic variability was analyzed in the Viannia subgenus by population-genetic parameters (Cupolillo et al. 1997). The level of polymorphism was $100 \%$, presenting a media of six alleles/loci. The relative level of genetic variability observed among the parasites indicates that they represent a heterogeneous group

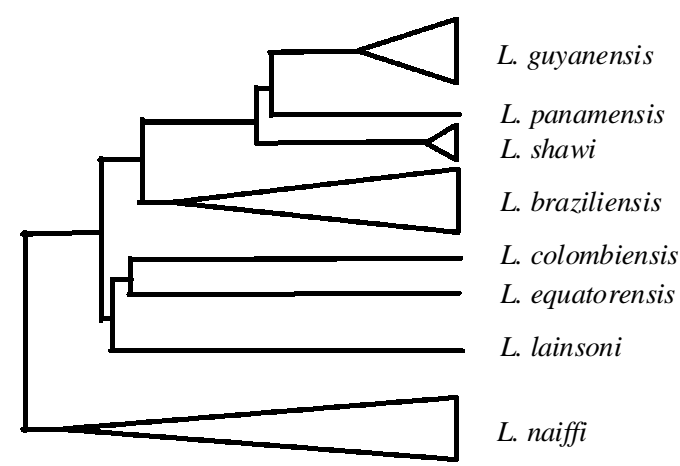

1.0

ITS Distance

Fig. 2: internal transcribed spacers (ITS) relationship and diversity in Leishmania (Viannia) species. of organisms. The level of heterozygosity observed $\left(H_{\mathrm{L}} \mathrm{obs}\right)$ among the zymodemes was 0.12 , whereas the level of heterozygosity expected $\left(H_{\mathrm{L}} \exp \right)$ would be 0.64 . If a population is in Hardy-Weinberg equilibrium, both the $H_{\mathrm{L}}$ obs and $H_{\mathrm{L}}$ exp would be similar. The relatively high values of $H_{\mathrm{L}} \exp$ and the striking differences found between $H_{\mathrm{L}} \mathrm{obs}$ and $H_{\mathrm{L}} \exp$ all pointed to the existence of a clonal structure in natural Leishmania populations (Selander \& Levin 1980, Tibayrenc \& Ayala 1988), reinforced by a strong linkage disequilibrium observed, indicating that asexual reproduction in Leishmania is far more common than sexual. Although it is evident that Leishmania has a clonal population structure, it does not exclude the possibility of sexual recombination. Our analysis of the MLEE data showed a large number of recurrent mutations in the Viannia parasites, which makes it reasonable to attribute some variation to recombination. Moreover, many authors have reported evidence of hybrid formation in Leishmania (Evans et al. 1987, Kelly et al. 1991, Darce et al. 1991, BonfanteGarrido et al. 1992, Dujardin et al. 1993, Belli et al. 1994, Noyes et al. 1996, Bañuls et al. 1997, Delgado et al. 1997), reinforcing the idea that sexual reproduction may occur in Leishmania, but at a level as yet undefined. It is important to emphasize that rare or occasional bouts of sexual recombination in a normally asexual organism can have a profound effect on the extent of genetic diversity (Cibulskis 1988).

Transmission cycle - A large number of Leishmania isolates have been characterized genetically and considerable variability detected. However, the epidemiolgy of leishmaniasis, in particular the transmission dynamics of the causative agents, is not completely understood. The transmission pattern of New World leishmaniasis involves two distinct cycles: sylvatic and urban. To understand better the role of animal reservoirs and hosts (vertebrate and invertebrate) in these cycles it is important to associated the variability in the parasite populations and the ecology of such endemic areas (Fig. 3).

Characterization by MLEE of L. chagasi isolates obtained from a variety of sources (humans, animals and sandflies) have indicated a low level of genetic variation (Momen \& Grimaldi 1989), while $L$. braziliensis isolates were highly polymorphic and $L$. naiffi showed intra-specific distances comparable to the largest obtained within all Viannia (Cupolillo et al. 1994, 1995, 1997). Interestingly, the same phlebotomine and mammalian species serve as vector and reservoirs of $L$. chagasi throughout its geographic range; with other parasites, such as L. braziliensis, several different sand fly and animal species are involved in distinct eco- 


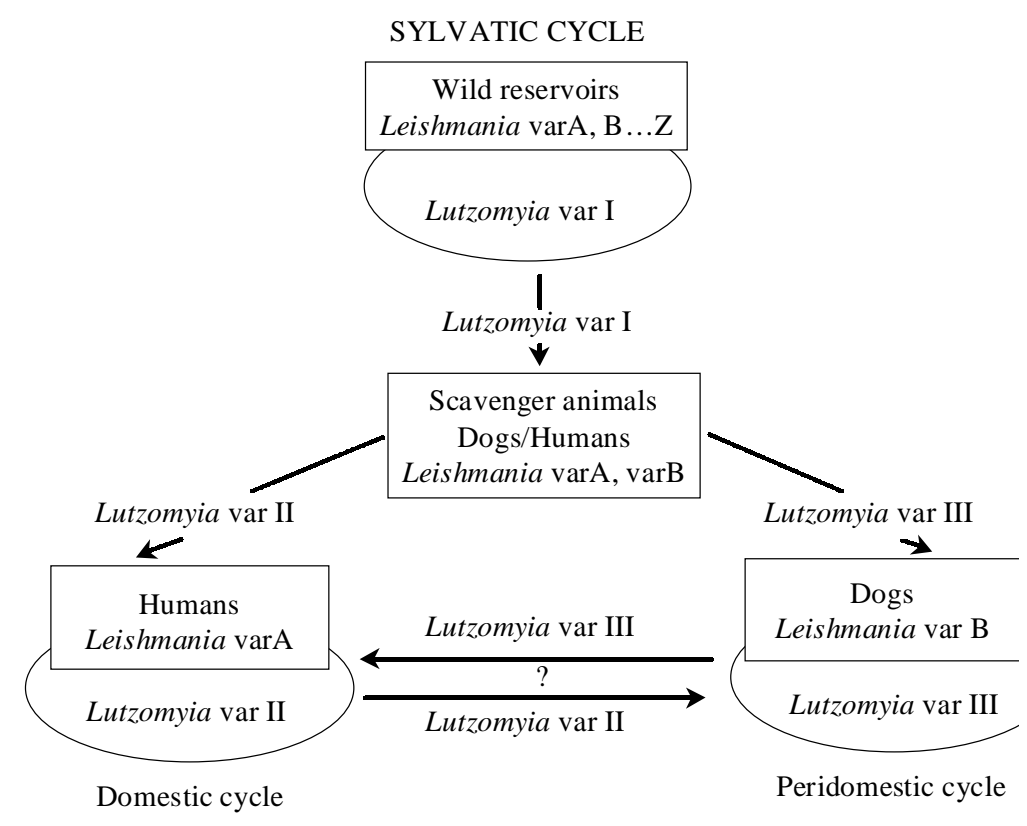

URBAN CYCLE

Fig. 3: hypothetical transmissions patterns of Leishmania.

logic and geographic regions. Our analyses revealed that the higher molecular diversity found in natural populations of a given Leishmania species is related with the higher number of sand fly vector(s) and/or animal reservoir(s) involved in the transmission cycle of the parasites (a co-evolutionary phenomenom?). In contrast, the L. braziliensis population circulating in the Brazilian Atlantic coast showed low levels of heterogeneity, and has Lutzomyia intermedia as the principal suspected vector. There is no apparent relationship between population heterogeneity in Leishmania and the capacity of the parasites to infect their hosts. Accordingly to Mayr (1973), the degree of genetic variability would be comparatively low in those parasites that were naturally selected in single hosts. Leishmania parasites may infect several species of host, both vertebrate and invertebrate (Lainson \& Shaw 1987, Grimaldi \& Tesh 1993). If specificity in the parasite-host relationship is important for Leishmania speciation, this process may also be involved in the genetic diversity found among these organisms.

Final comments - The strategies for the prevention and control of leishmaniases are basically the interruption of the transmission cycle (vector and/or reservoir control, personal protection, surveillance, treatment) and vaccination. The control of these diseases is impeded by the lack of vacci- nation or efficient treatment as well as by the sympatric distribution of Leishmania species, the zoonotic nature of the infection and the diversity of the transmission cycles. Although it is not yet evident that the molecular heterogeneity present in Leishmania is reflected in properties such as virulence, insect and vertebrate host specificity, geographic range, and drug sensitivity, this polymorphism could have profound consequences for the etiology and treatment of leishmaniases.

\section{REFERENCES}

Avise JC 1975. Systematic value of electrophoretic data. Syst Zool 23: 465-481.

Bañuls A-L, Guerrini F, Le Pont F, Barrera C, Espinel I, Guderian R, Echeverria R, Tibayrenc M 1997. Evidence for hybridization by multilocus enzyme electrophoresis and random amplified polymorphic DNA between Leishmania braziliensis and Leishmania panamensis/guyanensis in Ecuador. J Euk Microbiol 44: 408-411.

Belli AA, Miles MA, Kelly JM 1994. A putative Leishmania panamensis/Leishmania braziliensis hybrid is a causative agent of human cutaneous leishmaniasis in Nicaragua. Parasitology 109: 435-442.

Bonfante-Garrido R, Meléndez E, Barroeta S, Mejia de Alejos MA, Momen H, Cupolillo E, McMahon-Pratt D, Grimaldi Jr G 1992. Cutaneous leishmanisis in western Venezuela caused by infection with Leishmania venezuelensis and Leishmania braziliensis variants. Trans R Soc Trop Med Hyg 86: 141-148. 
Cibulskis RE 1988. Origins and organization of genetic diversity in natural populations of Trypanosoma brucei. Parasitology 96: 303-322.

Cupolillo E, Grimaldi Jr G, Momen H 1994. A general classification of New World Leishmania using numerical zymotaxonomy. Am J Trop Med Hyg 50: 296-311.

Cupolillo E, Grimaldi Jr G, Momen H 1997. Genetic diversity among Leishmania (Viannia) parasites. Ann Trop Med Parasitol 91: 617-626.

Cupolillo E, Grimaldi Jr G, Momen H, Beverley SM 1995. Intergenic region typing (IRT): a rapid molecular approach to the characterization and evolution of Leishmania. Mol Biochem Parasitol 73: 145-155.

Darce MJ, Moran X, Palacios A, Belli F, Gomez-Urcuyo F, Zamora D, Valle S, Gantier JC, Momen H, Grimaldi Jr G 1991. Etiology of human cutaneous Leishmaniasis in Nicaragua. Trans $R$ Soc Trop Med Hyg 85: 58-59.

Delgado O, Cupolillo E, Bonfante-Garrido R, Silva S, Belfort E, Grimaldi Jr G, Momen H 1997. Cutaneous leishmaniasis in Venezuela caused by infection with a new hybrid between Leishmania (Viannia) braziliensis and L. (V.) guyanensis. Mem Inst Oswaldo Cruz 92: 581-582.

Dujardin JC, Llanos-Cuentas A, Caceres A, Arana M, Dujardin JP, Guerrini F, Gomez J, Arroyo J, De Doncker S, Jacquet D, Hamers R, Guerra H, Le Ray D, Arevalo J 1993. Molecular karyotype variation in Leishmania (Viannia) peruviana: indication of geographical populations in Peru distributed along a north-south cline. Ann Soc Belge Med Trop 87: 335-347.

Dye C, Davis CR, Lines JD 1990. When are parasites clonal? Nature 348: 120.

Evans DA, Kennedy WPR, Elbihari S, Chapman C, Smith V, Peters W 1987. Hybrid formation in the genus Leishmania? Parassitologia 29: 165-173.

Gardner PJ 1977. Taxonomy of the genus Leishmania: a review of nomenclature and classification. Trop Dis Bulletin 74: 1069-1088.

Godfrey DC 1979. The zymodemes of trypanosomes. In Problems in the identification of parasites and their vectors. Symp Brit Soc Parasitol 17: 31-53.

Grimaldi Jr G, Tesh RB 1993. Leishmaniases of the New World: current concepts and implications for future research. Clin Microbiol Rev 6: 230-250.

Grimaldi Jr G, Tesh RB, McMahon-Pratt D 1989. A review of the geographic distribution and epidemiology of Leishmaniasis in the New World. Am J Trop Med Hyg 41: 687-725.

Guizani I, Van Eys GJJM, Ismail RB, Dellagi K 1994. Use of recombinant DNA probes for species identification of Old World Leishmania isolates. Am J Trop Med Hyg 50: 632-640.

Hurst LD, Hamilton WD, Ladle RJ 1992. Covert sex. Tree 7: 144-145.

Kelli JM, Law JM, Chapman CJ, Van Eys GJJM, Evans DA 1991. Evidence of genetic recombination in Leishmania. Mol Biochem Parasitol 46: 253-264.

Lainson R, Shaw JJ 1979. The role of animals in the epidemiology of the South American Leishmania- sis, p. 1-116. In HR Lumsden, DA Evans (eds). Biology of the Kinetoplastida, vol. 2, Academic Press, London.

Lainson R, Shaw JJ 1987. Evolution, classification and geographical distribution, p. 1-120. In W Peters, R Killick-Kendrick, (eds), The Leishmaniasis, In Biology and Epidemiology, Vol. 1, Academic Press, London.

Lopes UG, Momen H, Grimaldi Jr G, Marzochi MC, Pacheco RS, Morel CM 1984. Schizodeme and zymodeme characterization of Leishmania in the investigation of foci of visceral and cutaneous Leishmaniasis. J Parasitol 70: 89-98.

Macedo AM, Melo MN, Gomes RF, Pena SDJ 1992. DNA fingerprints: a tool for identification and determination of the relationship between species and strains of Leishmania. Mol Biochem Parasitol 53: 63-70.

Mayr E 1973. The recent historiography of genetics (Essay review). J Hist Biol 6: 125-154.

Mendoza-Leon A, Havercroft JC, Barker DC 1995. The RFLP analysis of the b-tubulin gene region in New World Leishmania. Parasitology 111: 1-9.

Momen H, Grimaldi Jr G 1989. Enzyme electrophoretic evidence for the importation of $L$. infantum into the New World, p. 911-916. In DT Hart, Leishmaniasis, Plenum, New York.

Noyes HA, Belli AA, Maingon R 1996. Appraisal of various random amplified polymorphic DNA-polymerase chain reaction primers for Leishmania identification. Am J Trop Med Hyg 55: 98-105.

Pacheco RS, Lopes UG, Morel CM, Grimaldi GJr, Momen H 1986. Schizodeme analysis of Leishmania isolates and comparison with some phenotypic techniques, p. 57-65. In J-A Rioux, Leishmania. Taxonomy and Phylogeny, IMEEE, Montpellier.

Richardson BJ, Baverstock PR, Adams M 1986. Allozyme Electrophoresis, Academic Press, Sydney, 403 pp.

Rioux J-A, Lanotte G, Serres E, Pratlong F, Bastien P, Perieres J 1990. Taxonomy of Leishmania using isoenzymes suggestions for a new classification. Ann Parasitol Hum Comp 65: 111-125.

Selander RK, Levin BR 1980. Genetic diversity and structure in Escherichia coli populations. Science 210: 545-547.

Sibley LD, Boothroyd JC 1992. Virulent strains of Toxoplasma gondii comprise a single clonal lineage. Nature 359: 82-85.

Thomaz-Soccol V, Lanotte G, Rioux J-A, Pratlong F, Martini-Dumas A, Serres E 1993. Monophyletic origin of the genus Leishmania Ross, 1903. Ann Parasitol Hum Comp 68: 107-108.

Tibayrenc M, Ayala FJ 1988. Isoenzyme variability in Trypanosoma cruzi, the agent of Chagas's disease: genetical, taxonomical, and epidemiological significance. Evolution 42: 277-292.

Tibayrenc M, Ayala FJ 1991. Towards a population genetics of micro-organisms: the clonal theory of parasitic protozoa. Parasitol Today 7: 228-232.

Tibayrenc M, Kjelberg F, Ayala FJ 1990. A clonal theory of parasitic protozoa: the populations structures of 
Entamoeba, Giardia, Leishmania, Naegleria, Plasmodium, Trichomonas and Trypanosoma and their medical and taxonomical consequences. Proc Natl Acad Sci USA 87: 2414-2418.

Tibayrenc M, Kjelberg F, Aranaud J, Oury B, Brenière
F, Dardé ML, Ayala FJ 1991. Are eukaryotic microorganism clonal or sexual? A population genetics vantage. Proc Natl Acad Sci USA 88: 5129-5133.

WHO-World Health Organization 1990. Control of the Leishmaniasis, WHO Tech Rep Ser 793. 